\title{
Diagnosis of cardiovascular autonomic neuropathy in diabetes: as simple as possible, but not simpler? An answer
}

\author{
G. $\operatorname{Bax}^{1}(D)$ F. Bellavere ${ }^{2}$
}

Received: 14 December 2018 / Accepted: 17 December 2018 / Published online: 8 February 2019

(c) Springer-Verlag Italia S.r.l., part of Springer Nature 2019

\section{Dear Editor,}

We read the interesting letter of K. Pafili and N. Papanas commenting on our recent paper on autonomic testing [1]. We appreciated that they reached somewhat similar conclusions in a previous work [2]: i.e., the association of HRV on Valsalva manoeuvre (VM) and on lying to standing (LS) is the most reliable tests for autonomic dysfunctions, although we found VM more sensitive than LS, in contrast to what they found.

However, we need to underline an important feature of our work: it is based on the ability of each test to recognize the presence "in the real world" of autonomic neuropathy, i.e., documented by the relief of postural hypotension. This marks an important difference from other previously published papers cited by K. Pafili and N. Papanas which, however, were based on "self-controlled" calculations within the five Ewing's tests: i.e., comparing the sensitivity (and specificity) of each test with the other tests in cross correlations within the battery itself in a questionable "closed loop".

Moreover, the clinical utility of VM and LS which we found pivotal in autonomic testing is confirmed by the paper of May and Arildsen [3] which shows the high independent predicting mortality value of VM and LS, while the deep breathing test results useless; just on the line and confirming what recently has come from the DIAD study, as mentioned in our paper $[4,5]$. Therefore, at least one question arises

Managed by Massimo Porta.

This reply refers to the comment available online at https://doi. org/10.1007/s00592-018-01279-1.

\section{G. Bax}

pino.bax@unipd.it

1 Diabetic Clinic USL 6 Euganea, DIMED University of Padova, Via dei Colli 4, 35143 Padua, Italy

2 Endocrinology and Diabetes section "Rizzola" Foundation Hospital, San Donà, Venezia, Italy from our paper and other recent evidences: is it necessary to use the deep breathing test anymore?

Hence, following our approach, the diagnosis in cardiovascular autonomic neuropathy results, we would say, simpler and clearer too.

\section{Compliance with ethical standards}

Conflict of interest The authors declare that they have no conflict of interest.

Ethical approval This article does not contain any studies with human participants performed by any of the authors.

Informed consent Informed consent was required before testing and obtained from any patient.

\section{References}

1. Bellavere F, Ragazzi E, Chilelli NC, Lapolla A, Bax G (2018) Autonomic testing: which value for each cardiovascular test? An observational study. Acta Diabetol. https://doi.org/10.1007/s0059 2-018-1215-y. (Epub ahead of print)

2. Pafili K, Trypsianis G, Papazoglou D, Maltezos E, Papanas N (2015) Simplified diagnosis of cardiovascular autonomic neuropathy in type 2 diabetes using Ewing's battery. Rev Diabet Stud 12(1-2):213-219

3. May O, Arildsen H (2011) Long-term predictive power of simple function tests for cardiovascular autonomic neuropathy in diabetes: a population-based study. Acta Diabetol 48(4):311-316

4. Chyun DA, Wackers FJ, Inzucchi SE et al (2015) Autonomic dysfunction independently predicts poor cardiovascular outcomes in asymptomatic individuals with type 2 diabetes in the DIAD study. SAGE Open Med 3:2050312114568476

5. Cha SA, Yun JS, Lim TS et al (2016) Diabetic cardiovascular autonomic neuropathy predicts recurrent cardiovascular diseases in patients with type 2 diabetes. PLoS One 11(10):e0164807

Publisher's Note Springer Nature remains neutral with regard to jurisdictional claims in published maps and institutional affiliations. 